\section{MS17 P20}

Structural aspects of solid state amorphization in $\mathbf{E u}_{2}\left(\mathbf{M o O}_{4}\right)_{3}$ europium molybdate. Elena Kudrenko ${ }^{l}$. Ivan Shmyt'ko, Vitaly Sinizyn, Evgeny Ponyatovsky and Boris Red'kin, Institute of Solid State Physics RAS, 142432 Chernogolovka, Moscow district. E-mail:lenak@issp.ac.ru

Keywords: rare-earth compounds, high-pressure amorphization, $x$-ray diffraction

The samples of $\mathrm{Eu}_{2}\left(\mathrm{MoO}_{4}\right)_{3}$ has been investigated by $\mathrm{X}$ ray diffraction method. These samples have been subjected high pressure $9 \mathrm{GPa}$ at room temperature. It was established that powder samples undergo at this pressure solid state amorphization. At consequent annealing with temperature increasing unusual sequence of phase states have been observed. Instead of expected "amorphous" $\rightarrow \alpha \rightarrow \beta$ sequence the "amorphous" $\rightarrow \beta \rightarrow$ $\alpha \rightarrow \beta$ sequence come to pass.

The single crystalline samples in contrast to polycrystalline ones do not undergo solid state amorphization. In this case phase transition from tetragonal $\beta$-phase into a new tetragonal high-pressure phase take place. We have shown that in the case of incomplete phase transition " $\beta$ - phase- high-pressure phase" two phase state has been characterized of existence of wide interphase boundaries. The parameters along the boundaries change continuously from one into other phase. In the case of complete phase transition into high-pressure tetragonal phase at subsequent annealing instead of narrow diffraction reflection halo-like reflections were observed. On the base of these results we have supposed that no amorphization in polycrystalline samples take place. The halo-like reflections in this case characterize the transitional state between high-pressure phase and $\beta$-phase, namely the diffraction from the set of transitional boundaries.

The work was supported by RFBR № 04-02-017143, 05-0208302 and 06-02-17298.

\section{MS17 P21}

3-D structural determination by powder diffraction on molybdopterin complex Jey Jau Lee*a ${ }^{* a}$ Hwo-Shuenn Sheu ${ }^{\mathrm{a}}$,Keng S. Liang ${ }^{\mathrm{a}}$, Baidyanath Ghosh ${ }^{\mathrm{b}}$ and Parag Sinchan Roy ${ }^{\mathrm{b}}$ a National Synchrotron Radiation Research Center Hsinchu 30076, Taiwan R.O.C. ${ }^{b}$. Department of Chemistry, University of North Bengal, Dist.- Darjeeling - 734013, India. E-mail:jjlee@nsrrc.org.tw

Keywords: molybdenum complexes, structure determination of coordination and pharmaceutical compounds, powder diffraction for unknown samples

The biological function of Molybdenum has been known to be contained in more than 30 distinct enzymes. The molybdenum-cofactor (Mo-co) consists of a mononuclear molybdenum ion coordinated by one or two molybdopterin ligands. Crystallographic results are very rare because of the crystal are very hard to grow up. The few results have demonstrated that the molybdopterin ligands are tricyclic and nonplanar, and that they coordinate the metal through their dithiolene sulfurs. The molybdopterin ligand may participate in the various electron transfer reactions associated with the catalytic mechanism of these proteins, as suggested by both oxidation state-dependent changes in the metal coordination environment and the molybdopterin structure, and by the interaction of the molybdopterin with other redox groups within Mo-co-containing enzymes. In here the 2-pivaloylamino-6-acetonyl- isoxanthopterin (1, $\mathrm{H}_{2} \mathrm{~L}$ ) has been reacted with $\mathrm{Na}_{2} \mathrm{MoO}_{4} \quad 2 \mathrm{H}_{2} \mathrm{O}$ under suitable conditions in presence of cysteine and $\mathrm{Ph}_{4} \mathrm{PBr}$ for synthesizing the new compound $\left(\mathrm{Ph}_{4} \mathrm{P}\right)_{2}\left[\mathrm{Mo}^{\mathrm{IV}}(\mathrm{L})(\mathrm{cys})_{2}\right] \cdot 0.5 \mathrm{CH}_{3} \mathrm{OH}$. Synchrotron powder diffraction studies throw light on its structural aspect. Here we report the 3-D structure determination of biomimic molybdenum coordination compounds from synchrotron powder diffraction data. The final refined space group is $\mathrm{P} 2_{1}, \mathrm{a}=16.2548(2), \mathrm{b}=10.7842(2)$, $\mathrm{c}=12.6836(1), \operatorname{Beta}=90.064^{\circ}, \mathrm{z}=2$. The asymmetric unit contains more than 400 atoms. The synthesis, reactivity and structure determination from synchrotron radiation powder diffraction will be shown and discussed.

[1].Edward I. Stiefel Science 272(1996), 1599

[2].J.H.Enemark, C.D.Garner J.Biol.Inorg.Chem. 2(1997), 817

\section{MS17 P22 \\ Crystal Structures of Synthetic Iron-bearing Tetrahedrites and Tennantites at $25^{\circ}$ and $250^{\circ} \mathrm{C}$ by Rietveld refinement of $\mathrm{X}$-ray and Neutron Diffraction Data Emil Makovicky a, Jens W. Andreasen ${ }^{\mathrm{b}}$, Tonci Balić- Žunić $^{a}$, Karen Friesec ${ }^{c}$, Andrzej Grzecnik ${ }^{c}$, Sven Karup- Møller ${ }^{\mathrm{d}}$, Bente Lebech ${ }^{\mathrm{b}}{ }^{a}$ University of Copenhagen, Denmark, $\quad{ }^{\mathrm{b}}$ Risoe National Laboratory, Roskilde, Denmark, ${ }^{\mathrm{c}}$ Universidad del País Vasco, Bilbao, Spain, \\ ${ }^{\mathrm{d}}$ Technical University of Denmark, Lyngby. \\ E-mail: emilm@geol.ku.dk}

Keywords: Rietveld refinement, tetrahedrite-tennantite, neutron diffraction

Tetrahedrite and tennantite are complex $\mathrm{Cu}-\mathrm{Sb}$ and $\mathrm{Cu}-\mathrm{As}$ sulphides with cubic symmetry and extensive substitutions of $\mathrm{Fe}, \mathrm{Zn}, \mathrm{Hg}, \mathrm{Ag}$ and other cations for copper. $\mathrm{Cu}^{\mathrm{S}} \mathrm{S}_{4}$ tetrahedra form a tetrahedral framework with large cavities which host clusters of $\mathrm{Cu} 2$ with three-fold coordination and lone electron pairs of $\mathrm{Sb}$ (As). These metalloids are positioned as $(\mathrm{Sb}, \mathrm{As}) \mathrm{S}_{3}$ pyramids in the cavity walls. In spite of extensive research, some fundamental questions, e.g., the structural role of $\mathrm{Fe}$, which starts the substitution process as $\mathrm{Fe}^{3+}$ and ends it as $\mathrm{Fe}^{2+}$, and the true nature of 'extremely anisotropic' $\mathrm{Cu} 2$ positions, remained in question.

Rietveld refinement of neutron powder diffraction data on four samples of synthetic, iron-bearing tetrahedrite with $0.40,1.06,1.23$, and 1.71 atoms $\mathrm{Fe}$ in the formula unit $\mathrm{Cu}_{10}(\mathrm{Fe}, \mathrm{Cu})_{2} \mathrm{Sb}_{4} \mathrm{~S}_{13}$ and four samples of synthetic tennantite with $0.12,0.50,0.84$, and 1.02 atoms $\mathrm{Fe}$ in the analogous formula unit with As instead of $\mathrm{Sb}$, indicates unambiguously that iron is incorporated into tetrahedral $\mathrm{Cu} 1$ sites and not into triangular $\mathrm{Cu} 2$ sites. The refinement results also confirm that $\mathrm{Cu} 2$ is a split, flat-pyramidal site situated statistically on both sides of the S1-S2 triangle. This split is about $0.6 \AA$ in tetrahedrite and about $0.7 \AA$ in tennantite. Unit cell volume and further structural trends have been evaluated by means of linear regression with $\mathrm{Fe}$ concentration as the independent variable.

Rietveld refinement of x-ray diffraction data from low-Fe and high-Fe samples of both compounds, obtained at ESRF 